\title{
Medical Students' Experiences of Teaching with Emotional Intelligence in Clinical Settings: A Qualitative Study
}

Nahid Toufan

Isfahan University of Medical Sciences

Athar Omid

Isfahan University of Medical Sciences

Fariba Haghani ( $\square$ fariba.haghani@gmail.com )

Isfahan University of Medical Sciences

\section{Research Article}

Keywords: Emotional intelligence, Clinical Teaching, Medical Student

Posted Date: March 16th, 2021

DOl: https://doi.org/10.21203/rs.3.rs-282020/v1

License: (a) (i) This work is licensed under a Creative Commons Attribution 4.0 International License. Read Full License 


\section{Abstract \\ Background}

Effective teaching in clinical environment is one of the challenges faced by clinical faculty members due to the complexities of the variables involved in the training. Using appropriate teaching methods by professors in this environment can promise efficient graduates in the field. The present study, as a follow up of Omid research, which designed a clinical teaching model based on emotional intelligence, was carried out to evaluate the results of implementing this model in a clinical setting.

\section{Methods}

A qualitative study was conducted using inductive content analysis in one of the educational hospitals affiliated with Esfahan University of Medical Sciences. A total of 20 volunteer medical students from different levels of education were selected using purposeful sampling and were asked to express their experiences of attending the round with its clinical teaching based on emotional intelligence. Participants included 4 stagers, 11 interns, and 5 residents. Data were collected using semi-structured individual interviews; each interview lasted for 40-60 minutes and began with the question: what do you think are the important features of this professor's clinical education? The following questions were asked based on the issues raised in the interview. Data collected were analyzed immediately after the interviews

\section{Results}

Two main categories emerged from data analysis: Health outcome and Learning outcome.

\section{Conclusion}

The use of teaching based on emotional intelligence in the clinical environment can be effective in promoting their learning while ensuring the health of the learners.

\section{Background}

Clinical teaching is an important part of medical education emphasizing on learning tangible and intangible skills [1]. Clinical environments include outpatient and inpatient wards. Traditionally, clinical teaching takes place in inpatient wards where a professor and his medical students gather at the patient's bedside to discuss his/her disease [2]. Given the importance of this issue, improving the quality of clinical education through faculty training should be considered as one of the most important policies considered by any medical institution [3]. Emotional intelligence is one of the most important capabilities that enables the clinical faculty members to solve the problems and daily life stresses helping them to have the best performance in interpersonal relationships and also to promote their professional performance 
[4].Emotional Intelligence (EI) not only enhances life satisfaction but increases satisfaction with education and a more positive attitude toward education, as well [5]. There are three levels to emotional intelligence: [1] the level of knowledge about emotions and emotional skills, [2] the ability to use knowledge in emotional situations, and [3] the tendency to use it in everyday life [6]. This competency helps teachers to better cope with stress and suffer from less burnout [7].Omid (2016), in her doctoral dissertation entitled "Teaching with emotional intelligence in clinical environment: Explaining, Training and Evaluating", introduced a model of clinical teaching based on emotional intelligence [8]. The current study is a continuation of Omid's work to examine the medical students' experiences of implementing this model by their medical instructors in the clinical environment.

\section{Methods}

Aim: To explain medical students' experiences of clinical teaching based on emotional intelligence.Design:Inductive content analysis was used to explain students' experiences of clinical teaching based on emotional intelligence. The learning environment in clinical learning is known to be a complex concept [9] and examining this setting qualitatively helps create a broad, deep, and comprehensive understanding of students' experiences of this teaching method.

\section{Setting:}

The present study was conducted in one of the hospitals affiliated with Isfahan University of Medical Sciences with medical students of different training levels, including externs, interns, and residents. The sections where the study was conducted included pediatric, internal medicine, emergency, heart, and poisoning.

\section{participants:}

The study participants consisted of medical students in different levels of training and professors of the selected clinical wards of the educational hospital. The residents, interns, and externs had passed at least one semester in the relevant section and the medical professors had at least one year of teaching experience in the ward. A total of 18 semi-structured individual and group interviews were conducted with 20 participants. Tables 1 and 2 shows participants' demographic details in separate groups.

Table 1: Demographic details of the interviewed participants (learners) 


\begin{tabular}{|c|c|c|c|c|c|}
\hline Gender & $\begin{array}{l}\text { Academic } \\
\text { grade }\end{array}$ & Gender & $\begin{array}{l}\text { Academic } \\
\text { grade }\end{array}$ & & \\
\hline 1 & Man & $\begin{array}{l}\text { Semester } 14 \\
\text { (intern) }\end{array}$ & 11 & Male & $\begin{array}{l}\text { Semester } 9 \\
\text { (Extern) }\end{array}$ \\
\hline 2 & Female & $\begin{array}{l}\text { Semester } 12 \\
\text { (intern) }\end{array}$ & 12 & Male & $\begin{array}{l}\text { Semester } 9 \\
\text { (Extern) }\end{array}$ \\
\hline 3 & Man & Senior resident & 13 & Female & $\begin{array}{l}\text { Semester } 14 \\
\text { (intern) }\end{array}$ \\
\hline 4 & Female & Senior resident & 14 & Female & $\begin{array}{l}\text { Semester } 14 \\
\text { (intern) }\end{array}$ \\
\hline 5 & Female & Junior resident & 15 & Female & $\begin{array}{l}\text { Semester13 } \\
\text { (intern) }\end{array}$ \\
\hline 6 & Female & Junior resident & 16 & Female & $\begin{array}{l}\text { Semester } 14 \\
\text { (intern) }\end{array}$ \\
\hline 7 & Man & $\begin{array}{l}\text { Semester } 12 \\
\text { (intern) }\end{array}$ & 17 & Male & $\begin{array}{l}\text { Semester } 14 \\
\text { (intern) }\end{array}$ \\
\hline 8 & Man & $\begin{array}{l}\text { Semester } 13 \\
\text { (intern) }\end{array}$ & 18 & Male & $\begin{array}{l}\text { Semester } 8 \\
\text { (Extern) }\end{array}$ \\
\hline 9 & Man & $\begin{array}{l}\text { Semester } 13 \\
\text { (intern) }\end{array}$ & 19 & Male & Semester 8 (intern) \\
\hline 10 & Man & $\begin{array}{l}\text { Semester } 10 \\
\text { (Extern) }\end{array}$ & 20 & Female & Senior resident \\
\hline
\end{tabular}

Table 2: Demographic details of professors participated in the study

\begin{tabular}{|llllll}
\hline Gender & $\begin{array}{l}\text { Specialized } \\
\text { field }\end{array}$ & Gender & $\begin{array}{l}\text { Specialized } \\
\text { field }\end{array}$ & & \\
\cline { 1 - 3 } & Female & $\begin{array}{l}\text { Infectious } \\
\text { disease }\end{array}$ & 6 & Female & Pediatrician \\
\hline 3 & Male & Poisoning & 7 & Male & Neonatal \\
\hline 4 & Female & Poisoning & 8 & Male & $\begin{array}{l}\text { Emergency } \\
\text { Medicine }\end{array}$ \\
\hline 5 & Male & $\begin{array}{l}\text { Infectious } \\
\text { disease }\end{array}$ & 9 & Male & Cardiologist \\
\hline
\end{tabular}

\section{Data collection:}

Data were collected through semi-structured interviews. The semi-structured interviews explored the views and experiences of the learners about clinical teaching with emotional intelligence. First, two workshops 
were held for volunteer professors and at the end of the workshop, they were given educational content in the field of teaching based on emotional intelligence, prepared by the researchers. This content included a package of clips, texts, scenarios, and a step-by-step guide to implement clinical teaching based on emotional intelligence. Attempts were also made to optimize the education using social networks.

The researcher was present in the clinical wards with an authorization letter signed by the heads of the relevant departments. She introduced herself as a medical education student seeking to evaluate the professor's teaching with the objective of enhancing the quality of clinical education. During this period, the researcher checked the correct implementation of the professors' teaching method using a checklist and gave them feedback. They were also given feedback through a WhatsApp group created for this purpose.

In addition, learners were selected using purposive convenience sampling. The interviews were held with the eligible candidates introduced as informants as well as the available volunteers. The interviews were conducted at a time and place convenient to the respondents making use of open-ended questions. Prior to the interviews, informed written consents were obtained from the participants after ensuring the right to withdraw from the study anytime in the study. At the request of four students, a group interview was performed about their experiences, too. The interviews continued until data saturation was reached, which was defined as the point after which no new information could be obtained from the interviews.

\section{Data analysis:}

Data analysis and data collection were conducted simultaneously using inductive content analysis. For the purpose of data analysis, the interviews were transcribed, coded, and analyzed separately. Each interview was read several times before assigning an initial code. The accuracy and acceptability of the data were increased by asking other researchers to read and code the transcribed interviews to ensure matching coding process.

Also, for the first four interviews, the coding results were sent to the interviewees to confirm the accuracy of the given codes. After the initial coding, the similar codes were categorized and labeled so that the labeling process would include and fit all the initial codes. The similar categories were placed together to form subcategories, and the subcategories were re-categorized to form the main categories. The researcher tried to confirm the trustworthiness of the findings using different ways. Credibility was checked by allocating sufficient time to data collection process (long engagement) and member check procedure. The long-term experience of two of the researchers (corresponding and the last authors) in clinical teaching with emotional intelligence proved useful in confirming the codes. Transferability was considered by precise transcription of the procedure, and dependability was strengthened by writing memos and coding data by two experts in qualitative research (external audit).

\section{Results}

The data analyses yielded two main categories and five subcategories as shown in Table 3. 
Table 3: Overview of the sub-categories, categories and themes which emerged in the study

\begin{tabular}{|lll|}
\hline Themes & Main Category & Subcategory \\
\hline Health outcome & Mental health improvement & Modifying emotions \\
\cline { 3 - 3 } & & Increasing interest and motivation \\
\hline \multirow{2}{*}{ Learning outcome } & Cognitive facilitation & increasing the self confidence \\
\cline { 2 - 3 } & Physical health improvement & Increasing physical health \\
\cline { 2 - 3 } & Professionalism Facilitation & Increasing comprehension \\
\cline { 2 - 3 } & & Promoting orbital ethics \\
\cline { 3 - 3 } & & Promoting interpersonal interactions \\
\hline
\end{tabular}

\section{Health outcome:}

From the students' point of view, one of the most important effects of teaching based on emotional intelligence was the effect on their health.

\section{Mental health improvement:}

Mental health improvement was reported among the significant effects of this type of teaching by the interviewees. This section includes modifying emotions, increasing interest and motivation, increasing self-confidence, and reducing mental conflict.

Increased positive and decreased negative emotions were repeatedly reported by the students in clinical wards where professors taught based on emotional intelligence. Examples of reported positive emotions included a sense of serenity, importance, joy, pride, belonging to a group, and usefulness. The most important reason for creating these feelings, as mentioned by the students, was the professor's attention and empathy toward their feelings as well as his emotional self-control and communication management.

"When the professor introduces both himself and you to the patient, it means that he cares about you. It gives the students a good feeling, as if they are important, too." (Sn 1, id code 92).

Negative emotions learners felt in the clinical wards included anxiety, confusion, guilt, being abused, forced labor, passivity, and feelings of inferiority. They believed that teaching based on emotional intelligence could prevent these negative emotions. 
"They understand us... For example, yesterday I was on a night shift in the hospital and I didn't sleep a wink, so this morning I was constantly falling asleep. I was one meter away from the professor when I fell asleep for a moment, but she did not humiliate me in front of you (the researcher) and the interns." (Sn: 3 , id code 16).

Increased interest and motivation and lively presence in the round was stated as another advantage of teaching based on emotional intelligence. Learners believed that the professor's attention to the basics of emotional intelligence in teaching could reduce their physical fatigue and prevent them from getting bored during the round. They attributed this to a) the professors considering students' emotions and showing empathy with them, b) the professors paying attention to the learners' physical and scientific needs, c) the professor's emotional self-management, and d) passion-based leadership.

Professors can also make the round more fruitful by paying attention to the duration of the round, the students' level in explaining scientific content, the students' physical comfort, assigning responsibility to them, and avoiding repetitive discussions in the round.

"The professor does not review repetitive lessons and we learn quite new things. This does not make us feel bored and we listen to the discussions eagerly." (Sn: 2 id code: 15$)$.

"Often, the professor motivates the students to try harder by, for example, giving them some topics for presentation." (Sn: 18-19 id code: 30$)$.

Another point that students mentioned among their useful experiences of teaching based on emotional intelligence was the increase in their self-confidence. Introducing the students to the patient, delegating responsibility to them, confirming their correct actions, and giving them feedback were reported as the main causes of the increase they felt in their self-confidence.

"When we made a correct diagnosis, the teacher encouraged us. It was really sweet for us to see our professor confirmed what was in our mind as a diagnosis and accepted us as a therapist. We gained the confidence to speak up again next time." (Sn 12 id code48).

Finally, participants suggested reducing mental conflict as a result of attending the round taught under the principles of emotional intelligence. Outside these rounds, the learners experience mental conflict as a result of the contradiction in the behavior and speech of the professors, which consequently leads to the reprimand of the students as they could not meet the professor's criteria.

In addition, learners introduced honesty, transparency, and professor's influence as other factors in reducing their mental conflict.

"Medicine is not just learning a science: it is also about dealing with the colleagues, the patients, and their families, even the ward cleaner. If the professor has many advantages but also a little of misbehavior, the lesson will not be easily engraved onto my mind. When I have a heartfelt relationship with a professor 
and I accept him, the behavior and speech of that professor are subconsciously engraved on my mind." (Sn 3 id code34, 35).

\section{Physical health improvement:}

Social Emotional awareness and communication management by the professor affect the learners' health. The professor's attention to the health and physical fatigue of the students can prevent the development and aggravation of their illness.

“Dr. .... is the only professor who realizes that you are tired or not. Once I wasn't feeling good, but no one noticed my problem. I was coughing all the time yet no one told me to go to have a drink. The only thing that matters to the medical personnel is to get over with the job and no one cares about us; this is what has been stuck on the minds of all of us" (Sn 5 id code 1,2).

Also, another participant argued that:

"In the hospital, we work as a team and the work of one person affects the whole team. For example, if the resident works effectively, both the patient and the professor will teacher benefit; if the resident doesn't work well, he can't visit the patient well either. On the other hand, if a student has an infectious disease, he can pass it on to the others. Therefore, careful attention should be paid to his health." (Sn 8 id code 40).

\section{Learning outcome:}

The second important effect of linking emotional intelligence to clinical teaching is students' learning outcomes, which is related to cognitive and professional facilitation.

\section{Cognitive facilitation:}

Cognitive facilitation occurs through increased comprehension and improved clinical reasoning. Interviewees acknowledge that clinical teaching with emotional intelligence increases their comprehension by developing accuracy and focus, active listening, increased study time, increased mental curiosity, and engaging in learning activities due to improved patient-student collaboration. Continuous mentoring, attention to the promotion of others, professor's emotional self-management, attention, and empathy with learner's emotions help the medical teacher to influence them which in turn increases students' comprehension. Also, the teacher's attention to the patient's emotions and showing empathy with him increases the patient's participation in education which in turn facilitates learning.

"Our learning depends on several factors: one is that we get to study well and the other is that we are not afraid to ask questions. This is very important. Sometimes the resident thinks that if he asks a question, the professor will assume that he doesn't know the answer! He may say 'You are a resident and you do not know this!' This humiliation does not allow anyone to ask questions." (Sn 6 id code 64).

Based on the experiences reported by the interviewees, in addition to giving them deep understanding of the materials, teaching based on emotional intelligence affected learners' clinical reasoning power. The 
flexibility of the professor in the assignments assigned and the assigning the responsibility of diagnosing and treating the patient to them was considered effective in this regard. It was also considered as an important cause in the reduction of direct supervision of professors allowing them to practice independently in promoting the power of clinical reasoning.

"The professor defends us and believes that as of now we are students who should first learn, and then, when the time comes, they can do the works required in the ward. Instead of forcing myself to report a document for nursing station, now I take the time to analyze the patient." (Sn 13 id code 46).

\section{Professionalism Facilitation:}

The present study showed that adding emotional intelligence to clinical teaching can enhance professionalism in learners by increasing ethics, improving interpersonal interactions, and increasing accountability.

The students believed that the professor's attention to ethics promoted their ethics. A professor who pays attention to the basics of emotional intelligence in clinical teaching is stronger in influencing his students and is more effective as a role model.

"When the teacher pays attention to the ethical points in dealing with nurses, we learn quite a lot. We learn that we should not brag after receiving our degree that, for example, as a doctor my job is more prestigious than a nurse's." (Sn 10, 11 id code25).

Improved interpersonal interactions in the clinical education triad (physician, student, and patient) was another experience reported by the students who participated in a clinical round taught based on emotional intelligence. They believed that the teacher's emotional self-awareness, social awareness, and attention to the needs of others contributed to this improvement.

"If the professor supports me on a tiring day, I will compensate for my falling back the other days when I am energetic and will try harder. This increases the relationship between the student and the professor. When the student-teacher relationship is favorable, everything takes a different color, and this is very important because a better communication between the professor and the learner results in more learning." (Sn 4 id code 73).

Finally, the participants considered their increased responsibility in learning owing to the professor's attention to their scientific promotion, provision of appropriate feedback, and attention to their nonscientific needs.

"The first day I was a little late, the doctor waited for me to come and we visited the patient together, although he was not my patient, this was a good experience because the student feels important and this feeling creates responsibility in him." (Sn 9 id code 59).

\section{Discussion}


The present study reports on the medical students' experiences of clinical teaching based on emotional intelligence. According to our results, the integration of emotional intelligence capabilities in clinical teaching not only ensures physical and mental health in medical students, but it also facilitates learning in them.

Emotional intelligence is associated with increased mental, physical, and general health in any general population including medical professionals [6]. People with higher emotional intelligence have better physical health because they are able to accurately understand their own and others' emotions and have the ability to manage emotional situations with exercise and a variety of relaxation activities [10].

The absence of negative indicators such as anxiety and depression as well as the presence of positive indicators such as resilience and work motivation indicate a mental health in an adolescent $[11,12,13,14]$. Also, emotional knowledge is shown to be associated with reduced depression [15]. In addition, compassion and suppression of anger is an example of a physician's therapeutic emotional therapy [16]. This is in line with the statements reported by the participants of our study. However, the effect of paying attention to the components of emotional intelligence by a clinical professor on physical and mind health of other people, such as students, has not been addressed in the previous studies.

Another main theme in this the current research was investigation of facilitating learning (including Cognitive facilitation and Professionalism Facilitation) in medical students.

Participants in the present study believed that teaching based on emotional intelligence improved their comprehension and cognitive facilitation by increasing their accuracy and concentration, active listening, increased study time, increased engagement with their learning activities, and increased mental curiosity.

As understood in cognitive sciences, emotions can play important roles in the formation of cognitive processes such as attention, perception, and memory. Today, it is known that the processing of emotions and cognition in the brain takes place in an integrated way, which results in the impact on behavior, especially memory, attention, and decision making [17].

Active listening is one of the most important components of communication skill and understanding situations is facilitated by proper attention. Teaching based on emotional intelligence stimulates active listening in students through positive regard, empathy, and readiness to serve others [18].

Furthermore, engagement can be defined as students' efforts to learn [19]. Facilitating student-patient relationships plays an essential role in shaping students' competencies and promoting high quality patient care [20]. In these relationships, students experience patient care and treatment, which in turn leads them to become professionals who can be of high quality as the primary caregiver, and provide safe and effective care [21]. Therefore, education strategies should focus on patient-centered care to facilitate relationships between patients and medical students for required essential competency. What motivates and empowers students and residents as future professionals to communicate well with patients is how the professor treats the patient as a role model. This both increases patient participation 
in education and provides safety care services for him. The power of the teacher's influence on the medical student is one of the components of teaching based on emotional intelligence.

Finally, curiosity can be described as a person's desire for information that interferes with the decisionmaking process [22]. The medical teacher can increase students' questioning by managing his emotions and paying attention to the promotion of others.

Clinical reasoning is the ability to reason accurately and make decisions. This ability, especially in emotional and difficult situations, is very important in providing safe and appropriate clinical care to patients [23]. Emotions play an important role in judgment and decision making, and especially in risky behaviors [24]. Participants believed that the teacher's flexibility in students' learning tasks and attention to student promotion by delegating responsibility to them could be effective in improving their clinical reasoning power. Continuous mentoring is one of the components of teaching based on emotional intelligence and adaptation to circumstances is also a sub-dimension of emotional intelligence [25].

Professionalism in physician is an inherent component of several of the ACGME competencies. In some studies, the relationships between El and Interpersonal and Communication Skills [26, 27], and learning how to manage and resolving conflict effectively have been mentioned [28].

The results of the current study showed that professional learning in medical students is enhanced by teaching based on emotional intelligence and it is considered to be related to professors paying attention

to the rules governing the organization, self-awareness, and social awareness. Moreover, paying attention to the students' promotion helps them to learn professionalism.

\section{Conclusion}

The clinical setting is a complex environment and medical education systems seek to train physicians with all the capabilities that are intended for them; however, these capabilities are not only the medical science. Paying attention to these two issues raises the need to use effective teaching methods appropriate for these challenges. The results of the present study showed that the link between clinical education and emotional intelligence is not only effective in the scientific advancement of medical students but also in their other essential abilities, such as interpersonal interactions and professionalism that are often overlooked in explicit training.

\section{Limitations And Strengths}

In the present study, we ascertained that participating students come from diverse levels of their medical training. In addition, including professors from different medical groups increased the validity of the collected data. Researchers also tried to attend the clinical environment and monitor the proper implementation of the clinical teaching based on emotional intelligence model. 
The strength of our research was investigation of the effect of teaching based on emotional intelligence by on students of different medical levels. To the best of our knowledge, this is the first study carried out in this field. Further studies can be conducted to improve knowledge in this area. Implementation of this model was concurrent with the Covid-19 pandemic in the world and Iran, which overshadowed medical education and caused a great deal of anxiety among students and professors. This condition could be considered an opportunity for researchers; however, this challenge limited the full-time presence of lowerlevel medical students and researchers in all wards of teaching hospitals.

\section{Declarations}

\section{Conflict of Interest Statement:}

The authors declare that the research was conducted in the absence of any commercial or financial relationships that could be construed as a potential conflict of interests.

\section{Acknowledgments:}

The authors would like to thank Dr. Hadi Azimi for their kindness in reviewing English as well as Isfahan University of Medical Sciences for supporting this research project and for all the study participants who helped us all.

\section{Funding:}

This study is based on a PhD thesis (Reference number: 397438) funded by the Research Department of Isfahan University of Medical Sciences.

\section{Availability of data and materials:}

The datasets generated and/or analysed during the current study are not publicly available due to their containing information that could compromise the privacy of research participants but are available from the corresponding author on reasonable request.

\section{Ethical statement:}

All participants gave written informed consent prior to participating. The study was approved by the Ethics Committee of Isfahan University of Medical Sciences, Isfahan, Iran, with the approval code number: 1397.178. The date of approval was 2018-12-23. Also, in this study all methods were carried out in accordance with relevant guidelines and regulations.

\section{Consent for publication:}

Informed consent was obtained from the participants prior to conducting study. All participants gave their informed consent for the research data to be included in a published article, without identifiable information. Informed consent was obtained from the participants prior to conducting study. 
Author contribution statement:

This research was conducted by a three-member team consisting of N.T. (as the first author), F.H. (as the corresponding author) and A.O. (as the second author). The idea for this research project came from F.H. and A.O. Review the texts, data Collection and Manuscript preparation was done by N.T and Design and Data analysis was performed by all authors. The text was edited by F.H. and A.O.

\section{Abbreviations}

El: Emotional Intelligence; Sn: Student number

\section{References}

1. Beigzadeh A, Bhaadinbeigy K, Adibi P, Yamani N. Identifying the challenges to good clinical rounds: $A$ focus-group study of medical teachers. Journal of Advances in Medical Education \& Professionalism. 2019;7(2):62. doi: 10.30476/JAMP.2019.44710

2. Arabshahi KS, Haghani F, Bigdeli S, Omid A, Adibi P. Challenges of the ward round teaching based on the experiences of medical clinical teachers. Journal of research in medical sciences: the official journal of Isfahan University of Medical Sciences. 2015;20(3):273. PMCID: PMC4468233

3. Arfaie K. Priorities of Clinical Education Evaluation from Nursing and Midwifery Students' Perspective. Iran Journal of Nursing (2008-5923). 2012;25(75).

4. Shukla S, Adhikari B, Ray M. Emotional Intelligence and Job Satisfaction: An Empirical Investigation. Amity Global HRM Review. 2016;6.

5. Mérida-López S, Extremera N, Rey L. Contributions of work-related stress and emotional intelligence to teacher engagement: Additive and interactive effects. International journal of environmental research and public health. 2017;14(10):1156.

6. Baudry AS, Grynberg D, Dassonneville C, Lelorain S, Christophe V. Sub-dimensions of trait emotional intelligence and health: A critical and systematic review of the literature. Scandinavian journal of psychology. 2018;59(2):206-22. https://doi.org/10.1111/sjop.12424

7. Omid A, Haghani F, Adibi P. Emotional intelligence: an old issue and a new look in clinical teaching. Advanced Biomedical Research. 2018;7. doi: 10.4103/2277-9175.225926

8. Omid A, Adibi p, Haghani F. Theaching with Emotional Intelligence in Clinical Environments: Explanation, Training and Evaluation: Esfahan Medical Univercity; 2016.

9. Huhn K, Gilliland SJ, Black LL, Wainwright SF, Christensen N. Clinical reasoning in physical therapy: a concept analysis. Physical therapy. 2019;99(4):440-56.

10. Hsiang R. Teachers' mental health: The relevance of emotional intelligence in burnout and quality of life. 2016.

11. Ruvalcaba NA, Gallegos J, Borges A, Gonzalez N. Extracurricular activities and group belonging as a protective factor in adolescence. Psicología Educativa. 2017;23(1):45-51. 
https://doi.org/10.1016/j.pse.2016.09.001

12. von Soest T, Mossige S, Stefansen K, Hjemdal O. A validation study of the resilience scale for adolescents (READ). Journal of Psychopathology and Behavioral Assessment. 2010;32(2):215-25. DOI 10.1007/s10862-009-9149-x

13. Botey M, Vaquero-Diego M, Sastre F. Perceived emotional intelligence of university professors based on the nature of the subject taught. Technological Forecasting and Social Change. 2020;161:120292. https://doi.org/10.1016/j.techfore.2020.120292

14. Kotera Y, Adhikari P, Van Gordon W. Motivation types and mental health of UK hospitality workers. International journal of mental health and addiction. 2018;16(3):751-63. https://doi.org/10.1007/s11469-018-9874-z

15. Davis SK, Humphrey N. The influence of emotional intelligence (EI) on coping and mental health in adolescence: Divergent roles for trait and ability El. Journal of adolescence. 2012;35(5):1369-79. https://doi.org/10.1016/j.adolescence.2012.05.007

16. McNaughton N. Discourse (s) of emotion within medical education: the ever-present absence. Medical Education. 2013;47(1):71-9.

17. LeBlanc VR, McConnell MM, Monteiro SD. Predictable chaos: a review of the effects of emotions on attention, memory and decision making. Advances in Health Sciences Education. 2015;20(1):265 82.https://doi.org/10.1111/j.1365-2923.2012.04329.x

18. Hemmerdinger JM, Stoddart SD, Lilford RJ. A systematic review of tests of empathy in medicine. BMC medical education. 2007;7(1):24. doi:10.1186/1472-6920-7-24

19. Maguire R, Egan A, Hyland P, Maguire P. Engaging students emotionally: The role of emotional intelligence in predicting cognitive and affective engagement in higher education. Higher Education Research \& Development. 2017;36(2):343-57. https://doi.org/10.1080/07294360.2016.1185396

20. Suikkala A, Leino-Kilpi H, Katajisto J, Koskinen S. Nursing student-patient relationship and related factors-A self-assessment by nursing students. Journal of Clinical Nursing. 2020;29(21-22):403044. https://doi.org/10.1111/jocn.15426

21. Johansson $B$, Mårtensson LB. Ways of strategies to knowing the patient described by nursing students. Nurse education in practice. 2019;38:120-5. https://doi.org/10.1016/j.nepr.2019.06.003

22. Leonard NH, Harvey M. The trait of curiosity as a predictor of emotional intelligence. Journal of Applied Social Psychology. 2007;37(7):1545-61. https://doi.org/10.1111/j.1559-1816.2007.00226.x

23. Hutchinson M, Hurley J, Kozlowski D, Whitehair L. The use of emotional intelligence capabilities in clinical reasoning and decision-making: A qualitative, exploratory study. Journal of clinical nursing. 2018;27(34):e600-e10.https://doi.org/10.1111/jocn.14106

24. Kusev P, Purser H, Heilman R, Cooke AJ, Van Schaik P, Baranova V, et al. Understanding risky behavior: the influence of cognitive, emotional and hormonal factors on decision-making under risk. Frontiers in psychology. 2017;8:102. 
25. Goleman D, Boyatzis R. Emotional intelligence has 12 elements. Which do you need to work on. Harvard Business Review. 2017;84(2):1-5.

26. Arora S, Ashrafian H, Davis R, Athanasiou T, Darzi A, Sevdalis N. Emotional intelligence in medicine: a systematic review through the context of the ACGME competencies. Medical education. 2010;44(8):749-64. https://doi.org/10.1111/j.1365-2923.2010.03709.x

27. Ravikumar R, Rajoura O, Sharma R, Bhatia MS. A study of emotional intelligence among postgraduate medical students in Delhi. Cureus. 2017;9(1). doi: 10.7759/cureus.989

28. Taylor C, Farver C, Stoller JK. Perspective: can emotional intelligence training serve as an alternative approach to teaching professionalism to residents? Academic Medicine. 2011;86(12):1551-4. doi: 10.1097/ACM.0b013e318235aa76 